\title{
Conclusions des rencontres RARE 2015
}

Didier Lacombe

Nous remercions beaucoup Gilles Roche et Caroline Morel. Ces rencontres revêtent aujourd'hui une importance significative et devront se poursuivre afin de permettre les échanges entre acteurs du monde académique, du monde associatif et du monde industriel dans le domaine des maladies rares.

\section{Xavier Tabary}

Au cours de ces rencontres - une première pour ce qui me concerne j'ai entendu des échanges très riches et intelligents. L'humanité qui se dégage de ces rencontres m'a procuré un grand bonheur. Je vous donne rendez-vous en 2017, car Eurobiomed continuera à soutenir ces rencontres sur les maladies rares. $\diamond$

\section{www.medecinesciences.org}

\section{OUI, je m'abonne à $\mathrm{m} / \mathrm{s}$}

Nom/Prénom :

Société :

Adresse :

$\mathrm{CP}$ : Ville :

E-mail (obligatoire) :

Je joins mon chèque de règlement (libeller votre chèque à l'ordre d'EDP Sciences)

Je règle par $\mathrm{CB}$ (paiement en ligne sécurisé sur site cf. section « abonnements ») Je souhaite recevoir une facture

\begin{tabular}{|c|c|c|c|c|}
\hline \multicolumn{2}{|c|}{ Abonnement } & France & UE & $\begin{array}{c}\text { Reste } \\
\text { du monde }\end{array}$ \\
\hline \multirow{2}{*}{ Particuliers } & $P+E$ & O $230 €$ & O $312 €$ & $312 €$ \\
\hline & $E$ & O $137 €$ & O $137 €$ & O $135 €$ \\
\hline \multirow{2}{*}{ Institutions } & $P+E$ & $539 €$ & O $657 €$ & $668 €$ \\
\hline & $E$ & \multicolumn{3}{|c|}{ Nous contacter } \\
\hline \multirow{2}{*}{ Étudiants* } & $P+E$ & O $122 €$ & O $172 €$ & ○ $194 €$ \\
\hline & $E$ & ○ $81 €$ & ○ $81 €$ & ○ $79 €$ \\
\hline \multirow{2}{*}{ Enseignants* } & $P+E$ & O $152 €$ & O $262 €$ & O $282 €$ \\
\hline & $E$ & $108 €$ & O $108 €$ & $107 €$ \\
\hline \multicolumn{3}{|c|}{$\begin{array}{l}P+E: \text { Papier et Électronique } \\
E: \text { Électronique }\end{array}$} & \multicolumn{2}{|c|}{ * joindre un justificatif } \\
\hline
\end{tabular}

À retourner à : EDP Sciences - Service abonnement

17, avenue du Hoggar - P.A. de Courtaboeuf - 91944 Les Ulis Cedex A, France

Tél. : +33 (0)1691875 75 - Fax : +33 (0)169860765 - abonnements@edpsciences.org 